\title{
University faculty and their knowledge \& acceptance of biological evolution
}

\author{
Justin W Rice ${ }^{1 *}$, Michael P Clough², Joanne K Olson², Dean C Adams ${ }^{3}$ and James T Colbert ${ }^{3}$
}

\begin{abstract}
Background: Misconceptions about biological evolution specifically and the nature of science in general are pervasive in our society and culture. The view that biological evolution explains life's origin(s) and that hypotheses become theories, which then become laws are just two examples of commonly held misconceptions. These misconceptions are reinforced in the media, in people's personal lives, and in some unfortunate cases in the science classroom. Misconceptions regarding the nature of science (NOS) have been shown to be related to understanding and acceptance of biological evolution.

Previous work has looked at several factors that are related to an individual's understanding of biological evolution, acceptance of biological evolution, and his/her understanding of the NOS. The study presented here investigated understanding and acceptance of biological evolution among a highly educated population: university faculty.

Methods: To investigate these variables we surveyed 309 faculty at a major public Midwestern university. The questions at the core of our investigation covered differences across and between faculty disciplines, what influence theistic position or other demographic responses had, and what model best described the relationships detected.

Results: Our results show that knowledge of biological evolution and acceptance of biological evolution are positively correlated for university faculty. Higher knowledge of biological evolution positively correlates with higher acceptance of biological evolution across the entire population of university faculty. This positive correlation is also present if the population is broken down into distinct theistic views (creationist and non-creationist viewpoints). Greater knowledge of biological evolution also positively correlates with greater acceptance of biological evolution across different levels of science education. We also found that of the factors we examined, theistic view has the strongest relationship with knowledge and acceptance of biological evolution.
\end{abstract}

Conclusions: These results add support to the idea that a person's theistic view is a driving force behind his or her resistance to understanding and accepting biological evolution. We also conclude that our results support the idea that effective science instruction can have a positive effect on both understanding and acceptance of biological evolution and that understanding and acceptance are closely tied variables.

Keywords: Science education; Faculty; Biological evolution; Theistic view; Creationism; Acceptance; Biology education

\section{Background}

The modern theory of biological evolution is an integral part of understanding the natural world. Yet, opinion polls consistently find that large portions of the public do not accept that evolution has occurred and is continuing to occur (Miller et al., 2006). Many students (in both high school and college) are: 1) not being given adequate instruction in biological evolution; 2) being taught inaccurate conceptions of biological evolution; and 3) being explicitly taught non-science material (e.g., creationism and intelligent design) in their science classes (Bandoli,

\footnotetext{
* Correspondence: justin.rice@palmer.edu

'Department of Life Sciences, Palmer College, Davenport, IA 52803-5287, USA Full list of author information is available at the end of the article
}

2008; Beardsley, 2004; Bowman, 2008; Cavanagh, 2005; Gross, 2006; Wallis, 2005).

Adding to the problem are the many common misconceptions about biological evolution. These include: 1) biological evolution explains the origin(s) of life; 2) biological evolution is an entirely random process; 3 ) knowledge of biological evolution will lead a person to become an atheist/act in an immoral fashion; 4) a controversy exists in the scientific community regarding the validity of biological evolution; 5) biological evolution is not observable/ testable; 6) Lamarckian evolution occurs; 7) the phrase "survival of the fittest" means those that are strongest, fastest, etc.; 8) individual organisms undergo biological evolution; 9) a positive directionality occurs in the process of biological evolution; and 10) our incomplete knowledge 
of biological evolution means that the entire theory is incorrect (Understanding Evolution, 2015).

Scientists and science educators have known about the problem surrounding biological evolution education (BEE) for decades. The misconceptions held by members of the public are not new, but within the last decade various events have drawn greater attention to the issue. Publications regarding BEE have increased, funding for BEE research has increased, and new BEE journals and conferences have appeared. While these developments are welcome, and will hopefully lead to improved BEE, considerable work remains.

Many groups have been surveyed in recent years, including introductory biology students, upper level biology students, high school biology teachers, pre-service secondary instructors, Christian clergy, and many others (Ingram and Nelson, 2006; Verhey, 2005; Brem et al., 2003; Colburn and Henriques, 2006; Barnesetal, 2009; Losh and Nzekwe, 2010). These studies have provided valuable insight into how these groups view and understand biological evolution, and suggest some avenues for addressing the issue. One group that has so far received little attention is the faculty at universities and colleges.

Faculty members at major research institutions are not only involved in the instruction of undergraduate students, but many are also active researchers at the forefronts of their chosen fields. Given the expectation that universities and colleges will provide the best possible education for students, we were surprised to find only one data set regarding higher education faculty knowledge of biological evolution (Paz-y-Miño and Espinosa $2011 \mathrm{~b}$ and 2012). In both studies the authors were interested in measuring the views of college faculty on biological evolution, as well as their views on several related topics (e.g. creationism and I.D.). They used newly developed surveys that they claim accurately measure faculty "views about evolution, creationism, and intelligent design, their understanding of how the biological evolution works, and their personal convictions". Previous work done in this field (Alters and Alters, 2001; Johnson and Peeples, 1987; Miller et al., 2006; Moore and Kraemer, 2005; Moore et al., 2009; Nehm and Schonfeld, 2007; Rice et al., 2011; Rudolph and Stewart, 1998; Sinatra et al., 2003; Sinclair and Pendarvis. 1998; Van Koevering and Stiel, 1989; Verhey, 2005; Zimmerman, 1987) has, however, demonstrated that accurately assessing views and understandings of biological evolution is challenging.

For instance, while Paz-y-Mino and Espinoza (both 2011b and 2012) provide an interesting data set, their work has limitations in that it did not differentiate between what types of faculty were responding to the survey. The type of faculty that respond to a survey may significantly impact the conclusions can be drawn from the resulting data. Whether their 244 respondents were non-biologists, biologists, or some mixture of both cannot be ascertained. Second, several of the questions examining viewpoints used a forced choice response with no option of a "none of the above" response, while one question on knowledge used forced choice between five incorrect answers. Neither of these survey question formats is appropriate for determining participants' views or knowledge (Hawkins and Coney, 1981; Tull and Hawkins, 1993). Therefore, further data on what faculty know, and accept, about biological evolution and the nature of science are needed.

Why should educators care what faculty at colleges and universities think about biological evolution? First, biological evolution is the unifying concept of the biological sciences and provides a useful context for making sense of the natural world. Second, from a medical perspective, biological evolution explains how humans are subject to natural selection, the origin of disease, resistance to antibiotics, viral function, and how to more effectively deal with current and future pathogens. Conservation, agriculture, environmental change, and forensics are just a few examples of other ways biological evolution informs our current understanding of the natural world. Biological evolution can be profitably addressed in any biologybased course, whether it be a general biology course for non-majors or a graduate level seminar on molecular biology. Biological evolution provides important context as the unifying idea in biology.

Understanding the views and knowledge of faculty is of particular importance for several reasons. First, understanding the relationship between faculty personal views, their area of expertise, their knowledge of biological evolution, and specific demographic factors will allow us to answer several important questions about BEE. Faculty members at colleges and universities come from many disparate fields of expertise and divergent educational backgrounds (e.g. biology, sociology, business). How those disparate experiences are associated with their current views regarding biological evolution may shed light on potential influence faculty outside biology may have on post-secondary students. If the instructors in charge of providing a tertiary education do not understand the material or have significant misconceptions about it, then they may be passing those misconceptions to students. That many students will ascribe a level of intellectual respect to those having earned an advanced degree (e.g., a doctorate) or are placed in charge of a college course, regardless of their area of expertise, is reasonable. This is reflected in creationists' attempts to find science and science-related faculty members to support their cause. But do these "experts" actually know what they are talking about? If we can learn what typical faculty members understand about biological evolution, what misconceptions they have, and how those are related 
to their personal views, their area of expertise, and other factors, we may gain insight regarding what must be done to improve post-secondary education.

Also reasonable is the expectation that faculty who expressly seek out a career in the biological sciences would understand more about biological evolution than their non-biology colleagues. Even though not every life science faculty member will be equally well-versed in biological evolution, all likely share an understanding of its fundamental tenets. These faculty ought to exhibit the best knowledge of biological evolution, compared to non- life scientist faculty, the general public, and students. This reasonable assumption has no data that support or refute it. What if, in a large population of postsecondary faculty, a few life science faculty members are determined to have a poorer understanding or acceptance of biological evolution than some non-life science faculty members? This would be a very damning indictment of the science programs that produced these biologists if they lack understanding of the fundamental ideas regarding biological evolution. How could we expect students to understand biological evolution if the instructors do not?

Clearly, a large portion of people in various groups do not accept biological evolution as either good science or as a viable explanation for the diversity of life on earth. Just as clear, many people (both scientists and non-scientists) presume a direct correlation between being a scientist (particularly a biologist) and accepting biological evolution. No data yet exist, however, to support this assumption. That non-scientists (e.g., business faculty) accept and/or understand biological evolution at a higher level than scientists (e.g., chemists) is plausible and deserving of study.

Previous work has also found correlations between an individual's knowledge of biological evolution and their acceptance of biological evolution (Lawson and Worsnop, 1992; Rice et al., 2011; Scharmann et al., 2005). This suggests that if we want to properly teach biological evolution, we must address both a population's knowledge and their acceptance of biological evolution.

Faculty directly impact the educational experience of their students, and some of those students go on to become K-12 teachers, post-secondary faculty members, policymakers, or hold other influential positions in society. Students who graduate from college with a poor knowledge of biological evolution may be given opportunities to teach (explicitly or not) about the topic and thus likely impart their misconceptions to their students. Understanding what misconceptions are common in university faculty, whether in science or other fields, is important for first understanding and then working toward improving post-secondary education of all students.

To investigate this phenomenon, we must first determine the strength of the correlation (if any) between knowledge of biological evolution and acceptance of biological evolution Second, if a correlation is present, we must understand its directionality. Finally, understanding what factors (e.g., subdivisions of the population) are driving differences from the overall model will help us address areas where improvement efforts may be focused.

The purpose of this study is to investigate the relationship, if any, between university faculty area of expertise, their knowledge of biological evolution, their acceptance of biological evolution, and several demographic factors. Specifically, the following questions guided the work reported here:

1. What knowledge of, and acceptance of, biological evolution do faculty members across various disciplines have?

2. How, if at all, does faculty members' knowledge of biological evolution differ between members of different disciplines?

3. How, if at all, does faculty members' acceptance of biological evolution differ between members of different disciplines?

4. What is the relationship, if any, between faculty members' theistic position and both their knowledge of, and acceptance of, biological evolution?

5. What is the relationship, if any, between faculty members' demographic responses and both their knowledge of, and acceptance of, biological evolution?

6. What model best describes the relationship between knowledge of biological evolution and acceptance of biological evolution?

\section{Methods}

\section{Study site}

Study participants were recruited from the full list of employees that were considered faculty at a major public Midwestern university during the 2010 - 2011 academic year. This definition was at the discretion of the Office of Institutional Research at the research site, and included 1595 potential participants. Faculty members were contacted via email where they were directed to voluntarily proceed to an online survey.

Data were kept anonymous; however participants were given the opportunity to submit another email contact for use in a random drawing for one of ten $\$ 50.00 \mathrm{gift}$ cards to a local bookstore. Data were collected over several months, with two reminder emails being sent to the potential participants. Relevant demographic data for the population as a whole was obtained from the Office of Institutional Research at the study site.

\section{Survey instrument}

The variables of interest in this study are participant knowledge of biological evolution, acceptance of biological 
evolution. In order to accurately measure both of those variables, distinct sets of questions are required.

We used an unmodified Knowledge of Evolution Exam (KEE) to measure participant knowledge of evolutionary concepts. The KEE has been used in previous studies and has been shown to be both a reliable and valid measure of a participant's knowledge of biological evolution for several different groups (Moore et al., 2009). The ten questions on the KEE cover content on biological evolution that would be familiar to students in an introductory college biology course.

To assess acceptance of biological evolution, we used an unmodified version of the Measure of Acceptance Toward Evolution (MATE). The MATE has also been used in previous studies measuring acceptance of biological evolution and has been shown to be a valid and reliable measure (Rutledge and Sadler, 2007; Moore and Cotner, 2009a; Moore and Cotner, 2009b). The twenty questions on the MATE examine the participants' views of whether humans and other animals have evolved, whether biological evolution is science, the age of the Earth, whether biological evolution is testable, and other related views.

A section of the survey was devoted to measuring participant understanding of the nature of science (NOS). Understanding of NOS has been previously shown to be related to an individual's knowledge and acceptance of biological evolution, and thus was of interest. This portion of the survey was based on the Student Understanding of Science and Science Inquiry (SUSSI) and had several alterations (Liang et al., 2008). This section was placed at the beginning of the survey so as to avoid any potential negative bias associated with a discussion of biological evolution. This portion of the survey was intended to address research questions beyond the scope of this manuscript, and will be reported elsewhere.

In total, the survey used here consisted of 54 multiplechoice questions and 7 text response questions. Besides the KEE, MATE, and SUSSI sections, three other questions examined participant views of educational policies, public acceptance/rejection of biological evolution, and their personal theistic view. Five questions at the end of the survey were of a demographic nature (sex, age, area of expertise, employment level, and amount of science education received). Of the seven text response questions, three were relevant to the MATE and KEE portions while the remaining four were relevant to the SUSSI portion and thus are not discussed here.

309 complete surveys were received from the 1595 faculty members contacted. An additional 139 incomplete surveys were also collected; however, none of these responses reached a level of completeness to be useable in the analyses.

The resulting sample was examined both as a whole and in specific subgroups. The demographic and theistic view questions allowed the sample to broken down into specific categories of interest: area of expertise, theistic view, and amount of science education. Participants were grouped for area of expertise according to their response to the question: "What is your area/field of work? (e.g. Chemistry, History, etc.)". Based on the responses, participants were grouped together into the following categories: Social Science (e.g., Economics, Psychology, Education, and History), Physical Science (e.g., Physics, Chemistry and Geology), Business (e.g., Finance, Marketing, and Accounting), Applied Science/Engineering (e.g., Civil Engineering, Aerospace Engineering, and Industrial Engineering), Life Science (e.g., Agronomy, Cell Biology, Genetics, and Horticulture), Humanities (e.g., Music, Theatre, English, and Philosophy), Veterinary Medicine, and those that did not answer. Twenty eight responses were collected that did not fit in this categorization scheme and were too few in number to warrant inclusion as their own group (e.g., Information Systems, Statistics). Of these 28, all were placed in the "Not Answered" category.

For theistic view, the survey provided several possible categories: Young Earth Creationist, Old Earth Creationist, Theistic Evolutionist, Agnostic Evolutionist, Atheistic Evolutionist, and a not answered/other group. This categorization scheme is based on a similar set of categories described by Scott (2005). During the analysis, these six categories were reduced to four, for two main reasons. First, in our opinion the distinction between some of the full six categories were not relevant to the primary research questions being considered. Second, using the full six categories would have left some categories too small to be statistically useful. Therefore, Young Earth Creationist and Old Earth Creationist were placed into one group, Theistic Evolutionist was a second group, Agnostic Evolutionist and Atheistic Evolutionist was a third group, and the Not Answered/Other responses were a fourth group.

The amount of science education included the following four choices: 9 or more science courses, 5-8 science courses, 1-4 science courses, or no science courses. The results from the KEE and MATE portions of the survey were summed into percentage scores for the analyses reported below, unless otherwise noted.

\section{Statistical analyses}

In this study, we were interested in measuring the relationship between knowledge of biological evolution and acceptance of biological evolution across several variables, including theistic position, amount of science education, and area of expertise. In order to assess the overall relationship between knowledge of biological evolution and acceptance of biological evolution, we used a simple linear regression comparing the percentage scores of all the participants on the knowledge of biological 
evolution measure to their percentage scores on the acceptance of evolution measure. In addition, we performed an ordination analysis to obtain a graphical visualization of the patterns present in the data. For this, we first created a distance matrix among individuals by calculating pairwise Jaccard's distance between individuals, based on participant responses to each question. We then used principal coordinate analysis (PCoA) to generate an ordination of the response data space. Individual participants were then color-coded by grouping variables to provide a visual examination of whether or not a particular group displayed similar responses to the questionnaire.

One-way ANOVAs were then used to examine several relationships. First, we tested for the presence of a significant relationship between the percentage scores for participant knowledge of biological evolution by their theistic view; their area of expertise; and the amount science education they reported. Second, we tested for the presence of a significant relationship between the percentage scores for participant acceptance of biological evolution by their theistic view; their acceptance of biological evolution; their area of expertise; and the amount of science education they reported.

In order to identify potential interaction between the grouping factors of area expertise and theistic viewpoint, two-way ANOVAs were performed. These tests were used to examine whether the relationships described in the one-way ANOVAs were the same or different when another variable was considered. As with prior analyses, two-way ANOVAs were performed separately on survey questions relating to: 1) knowledge of biological evolution, and 2) acceptance of biological evolution. Mantel tests were also performed on separate distance matrices of the participant responses to the knowledge and acceptance portions of the survey to assess the degree of association between participant scores on the knowledge of evolution, acceptance of evolution, and the grouping variables of area of expertise and theistic view. Specifically, Mantel correlations were calculated between knowledge of biological evolution and acceptance of biological evolution across all participants; between knowledge of biological evolution and acceptance of biological evolution for those participants with differing theistic views (e.g., creationist); and between knowledge of biological evolution and acceptance of biological evolution for each area of expertise (life science, humanities, etc.).

In order to identify potential interaction between the grouping factors of theistic viewpoint and amount of science education, two-way ANOVAs were performed. Again, these tests were used to examine whether the relationships described in the one-way ANOVAs were the same or different when another variable was considered. As with prior analyses, two-way ANOVAs were performed separately on survey questions relating to: 1) knowledge of biological evolution, and 2) acceptance of biological evolution. Mantel tests were also performed on separate distance matrices of the participant responses to the knowledge and acceptance portions of the survey to assess the degree of association between participant scores on the knowledge of evolution, acceptance of evolution, and the grouping variables of theistic view and amount of science education. In this case Mantel correlations were calculated between knowledge of biological evolution and acceptance of biological evolution across all participants; between knowledge of biological evolution and acceptance of biological evolution for those participants with differing theistic views (e.g., young earth creationist); and between knowledge of biological evolution and acceptance of biological evolution by how much science education participants reported.

One-way ANOVA tests were used to examine whether participant knowledge of biological evolution and acceptance of biological evolution were different between each category of interest (theistic view, area of expertise, amount of science education). Linear regression was also used to identify the relationship between variables such as between knowledge of biological evolution and acceptance of biological evolution for physical scientists. Since we are interested in seeing which factors explain the variation we see in the data (e.g., does amount of science or theistic view have more impact on an individual's knowledge of biological evolution and acceptance of biological evolution), we used Akaike Information Criterion (AIC) to compare the fit of the resulting models. Specifically, we used AIC to compare models based on participant theistic view, area of expertise, or amount of science education regarding their fit to participant knowledge of biological evolution and acceptance of biological evolution. We also used permutation tests to examine whether the observed results from some specific tests were significantly different from a random result.

Finally, pairwise t-tests were used to compare the knowledge of biological evolution and acceptance of biological evolution of the participants between each area of expertise as well as within each area of expertise but between their theistic views (e.g. creationist business faculty compared to non-creationist business faculty).

All statistical computations and procedures were performed in R 2.12.1 (R Core Team 2014).

\section{Results}

\section{Quantitative results}

The participants in the resulting sample aligned very closely with previously known information regarding the population as a whole. Two points of difference are worth noting. First, the participants were $47.4 \%$ female and $52.6 \%$ male, but the population of faculty at this study site is $35.1 \%$ female and $64.9 \%$ male. This means a 
disproportionate number of female faculty members completely the survey compared to their male counterparts. No differences between any variable of interest were detected when sex was considered, but given that our sample was not sex-representative of the population those may not be accurate results. Second, less than $5 \%$ of the participants stated their area of expertise was in or related to Veterinary Medicine but approximately $11 \%$ of faculty at this study site hold that specialty. Other areas of expertise were more accurately represented in the sample $(24.7 \%$ Life Scientists; $18.8 \%$ Social Scientists; $12.5 \%$ Humanities; 11.1\% Engineering; 10\% Physical Scientists; 5.1\% Business; 4.7\% Veterinary Medicine; 13.1\% Not Answered/Other).

The overwhelming majority (66.9\%) of participants chose the Agnostic Evolutionist theistic view, with no other views exceeding $11 \%$ of the participants $(2.9 \%$ Young Earth Creationist; 2.9\% Old Earth Creationist; 9.8\% Theistic Evolutionist; 7.3\% Atheistic Evolutionist; 10.2\% Not Answered/Other). The majority (53.1\%) of participants also stated that they had received a large amount (nine or more courses) of science education, with the next largest portion being those with a low amount (one to four courses) of science education $(27.5 \%)$, followed by the medium amount (five to eight courses) of science education (13.1\%), and lastly those with no science education (6.3\%). The participants were largely tenured faculty $(58.3 \%$, tenure track: $18.7 \%$, nontenure track: $23 \%)$ as well as Caucasian $(81.1 \%$, Asian: 14.1\%, All other options: $4.8 \%$ ).

As a whole, the faculty scored an average of $68 \%$ correct on the knowledge of biological evolution portion of the survey. They scored an average of $86.8 \%$ agreement with statements measuring acceptance of biological evolution (Additional file 1: Table S1). Both measures are right-shifted toward the higher end of the scale, with approximately $45 \%$ of the knowledge of biological evolution scores lying to the right of the average, and approximately $60 \%$ of the acceptance of biological evolution scores lying to the right of the average. This means we should not have bias in our results from having a population with an unbalanced distribution of scores.

\section{Results part 1: single factor tests}

Using simple linear regression we found a significant association between knowledge of biological evolution and acceptance of biological evolution $\left(\mathrm{F}_{1,307}=145.07\right.$, $\mathrm{R}^{2}=0.3204, \mathrm{p}<0.001$; Pearson's $\mathrm{r}=0.566$ ) (Figure 1). High knowledge of biological evolution was strongly correlated with high acceptance of biological evolution. Likewise, a significant relationship between knowledge of biological evolution and acceptance of biological evolution was revealed using a Mantel test $(r=0.469$; $\mathrm{p}<0.001)$.

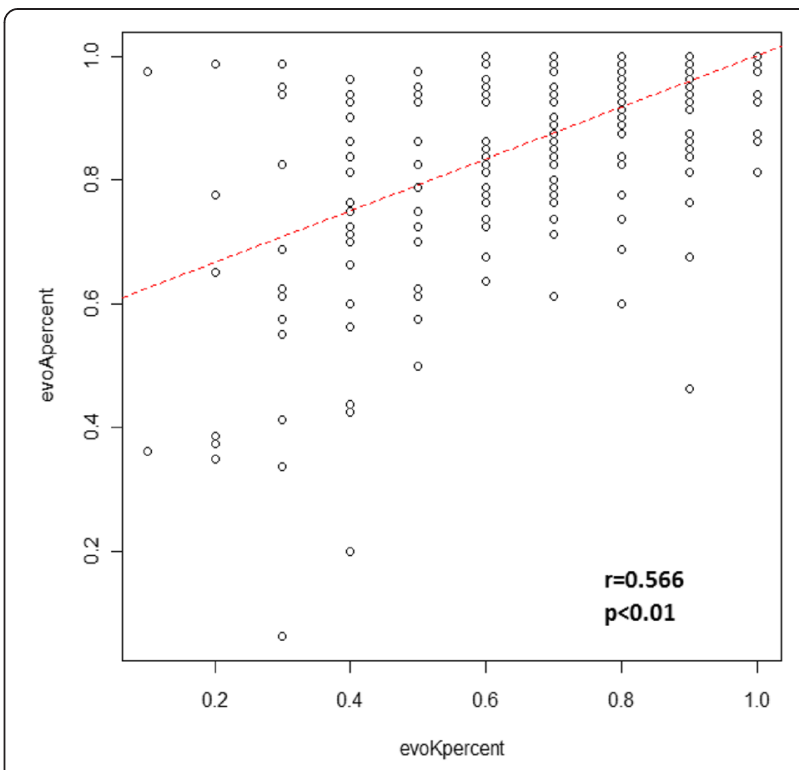

Figure 1 Simple linear regression of knowledge of biological evolution by acceptance of biological evolution. evoApercent = participant scores on the measure of acceptance of biological evolution as a percentage. evoKpercent = participant scores on the measure of knowledge of biological evolution as a percentage.

\section{Tests by theistic view}

Analysis of variance revealed that faculty grouped by theistic views differed in their knowledge of evolution and acceptance of evolution (Table 1). In all but one case, participants with a more creationist theistic view had a lower average knowledge of biological evolution $(\mathrm{p}<0.001)$ (Table 2). In all cases, participants with a more creationist theistic view had a significantly lower average acceptance of biological evolution $(\mathrm{p}<0.001)$ (Table 3).

Likewise, a significant relationship between knowledge of biological evolution and acceptance of biological evolution was revealed using a Mantel test for each group in the schema (Additional file 1: Table S2). As above, the one exception in the case of knowledge of biological evolution was in the comparison between the participants with creationist views and the participants with theistic evolutionist views (Table 1). In that case, no significant differences were detected in the knowledge of biological evolution between the participants $\left(\mathrm{F}_{1,49}=2.5928\right.$, $\mathrm{p}=0.1138)$.

\section{Tests by area of expertise}

Using one-way ANOVA to examine the relationship between the percentage scores for participant knowledge of biological evolution, acceptance of biological evolution, and their area of expertise, significant differences exist in the knowledge of biological evolution among faculty grouped by their area of expertise $\left(\mathrm{F}_{8,273}=2.3537\right.$, $\mathrm{p}<0.05)$ but no differences in their acceptance of biological evolution $\left(\mathrm{F}_{8,273}=1.7659, \mathrm{p}=0.08376\right)$. 
Table 1 Statistical results from ANOVA examining participant knowledge of biological evolution and acceptance of biological evolution by their theistic viewpoint using the schema

\begin{tabular}{lllll}
\hline & Knowledge of B. Evolution & Significance & Acceptance of B. Evolution & Significance \\
\hline Theistic View: (All Groups) & $F_{2,279}=28.745$ & $p<0.001$ & $F_{2,279}=136.70$ & $p<0.001$ \\
Theistic View: (Creationist vs. Theistic Evolutionist) & $F_{1,49}=2.5928$ & $p=0.1138$ & $F_{1,49}=27.921$ & $p<0.001$ \\
Theistic View: (Theistic Evolutionist vs. Non-Creationist) & $F_{1,263}=28.904$ & $p<0.001$ & $F_{1,263}=71.344$ & $p<0.001$ \\
Theistic View: (Creationist vs. Non-Creationist) & $F_{1,246}=35.478$ & $p<0.001$ & $F_{1,246}=259.19$ & $p<0.001$ \\
\hline
\end{tabular}

Using pairwise t-tests, the only significant difference in knowledge of biological evolution was between the participants who identified their area of expertise as "Life Science" who scored significantly $(\mathrm{p}<0.05)$ higher on the measure of knowledge of biological evolution than those who did not identify their area of expertise (Table 2). The pairwise t-tests used to compare average scores of participants in each area of expertise with each other also revealed that while a one-way ANOVA was unable to detect any significant differences in participant acceptance of biological evolution between the areas of expertise, they did exist. Specifically, participants who identified as "Social Science" scored significantly $(\mathrm{p}<0.05)$ higher on the measure of acceptance of biological evolution than those who did not identify their area of expertise (Table 2).

Using linear regression we found that knowledge and acceptance were significantly positively correlated for all areas of expertise (Additional file 1: Table S3). Likewise a significant relationship between knowledge of biological evolution and acceptance of biological evolution was revealed using a Mantel test for each area of expertise except those participants who identified their area of expertise as Veterinary Medicine (Additional file 1: Table S4).

\section{Tests by other demographic variables}

One-way ANOVAs were used to examine the relationship between the percentage scores for participant knowledge of biological evolution, acceptance of biological evolution and the various demographic variables that were measured. We found no significant relationships except in the case of the amount of science education participants reported. While both participant age and employment level were weakly related to participant acceptance of biological evolution, the strength of the relationship was not large enough to warrant further investigation.

\section{Tests by amount of science education}

Pairwise t-tests revealed that those participants that reported a high level of science education (nine or more courses) scored significantly higher on the measure of knowledge of biological evolution than those who reported a low level of science education (one to four courses) (Additional file 1: Table S5). The pairwise t-tests using average scores of participants by their amount science education also revealed that participants that reported a high level of science education (nine or more courses) scored significantly higher on the measure of acceptance of biological evolution. This is compared to either those who reported a moderate level of science education (five to eight courses) or a low level of science education (one to four courses) (Additional file 1: Table S5).

One-way ANOVA tests were then used to examine how knowledge of biological evolution and acceptance of biological evolution were related for each amount of science education participants reported. Using linear regression calculate the magnitude and direction of the correlation between variables (such as between knowledge and acceptance of biological evolution for those reporting a high amount of science education), we found that knowledge and acceptance were significantly positively correlated for all groups except those that reported no science education (Additional file 1: Table S6). Mantel tests between knowledge and acceptance of biological evolution by how much science education participants showed that there are significant positive correlations between knowledge and acceptance for high, moderate and low amounts

Table 2 Knowledge and Acceptance Scores by Area of Expertise (* significantly different at $\mathbf{p}<0.05$ )

\begin{tabular}{|c|c|c|c|c|c|c|c|c|}
\hline & $\begin{array}{l}\text { Life } \\
\text { science }\end{array}$ & $\begin{array}{l}\text { Social } \\
\text { science }\end{array}$ & $\begin{array}{l}\text { Physical } \\
\text { sciences }\end{array}$ & Engineering & Business & Humanities & $\begin{array}{l}\text { Veterinary } \\
\text { medicine }\end{array}$ & $\begin{array}{l}\text { Not } \\
\text { answered }\end{array}$ \\
\hline $\begin{array}{l}\text { Mean Knowledge of Biological } \\
\text { Evolution Score }\end{array}$ & $74.3 \% *$ & 72.1 & 70.3 & 65.3 & 64.7 & 62.9 & 60.8 & $58.8^{*}$ \\
\hline $\begin{array}{l}\text { Mean Acceptance of Biological } \\
\text { Evolution Score }\end{array}$ & 87.6 & $91.4^{*}$ & 90 & 86 & 84.1 & 85.6 & 88.5 & $78.8^{*}$ \\
\hline
\end{tabular}


Table 3 Mean percentage scores on measures of knowledge of biological evolution and acceptance of biological evolution by theistic view groupings used in the schema

\begin{tabular}{lll}
\hline & $\begin{array}{l}\text { Mean knowledge } \\
\text { of B. Evolution }\end{array}$ & $\begin{array}{l}\text { Mean acceptance } \\
\text { of B. Evolution }\end{array}$ \\
\hline $\begin{array}{l}\text { Creationists (Young Earth } \\
\text { Creationists and Old Earth }\end{array}$ & $43.53 \%$ & $39.12 \%$ \\
$\begin{array}{l}\text { Creationists) } \\
\text { Theistic Evolutionists }\end{array}$ & 54.12 & 60.82 \\
$\begin{array}{l}\text { Non-Creationists (Agnostic } \\
\text { Evolutionists and Atheistic }\end{array}$ & 72.68 & 73.53 \\
Evolutionists) & & \\
\hline
\end{tabular}

of science education (Additional file 1: Table S7). This corroborates the results from the one-way ANOVA and linear regression.

\section{Principle coordinates analysis}

The pattern seen in the PCoA of participant responses on knowledge and acceptance measures displayed a distinct shape and curve. The distinct shape of the plot suggested that some other variable might be driving accounting for the variation seen along axis PCoA 1 (35\% of the variation, PCoA 2 explains 7\% of the variation). When participant responses were coded by their response to other questions on the survey (theistic view, opinion of teaching ID, sex, etc.) one label appeared to fit with the greatest variation being along the PCoA 1 axis, participant theistic view (Additional file 2: Figure S1).

Results part 2: tests of the impact of multiple factors Tests by theistic view and area of expertise

Using two-way ANOVAs, we found theistic view had a far more pervasive effect on participant knowledge of biological evolution than area of expertise. This was also the case for participant acceptance of biological evolution (Table 4). However, in the case of acceptance of biological evolution, the significant interaction term for theistic view and area of expertise was detected and represents that acceptance of biological evolution does change by theistic view, but only for those participants who identified as "other". If those participants are removed then no interaction term is detected.

\section{Tests by theistic view and other variables}

Two-way ANOVAs also revealed that theistic view has a more pervasive effect on participant knowledge of biological evolution than their amount of science education reported. This was also the case for participant acceptance of biological evolution (Table 5). Again, in the case of acceptance of biological evolution, a significant interaction term for theistic view and amount of science education was detected and represents that acceptance of biological evolution does change by theistic view, but only for those participants who reported "none" for their amount of science education. If those participants are removed then no interaction term is detected.

When these two-way ANOVAs are performed using the schema for theistic view, the resulting patterns are the same. Theistic view had a far more pervasive effect on participant knowledge of biological evolution than either area of expertise or amount of science education. Theistic view also had a more pervasive effect on participant acceptance of biological evolution than either area of expertise or amount of science education. In the case of acceptance of biological evolution, a significant interaction term for theistic view and area of expertise was detected and represents that acceptance of biological

Table 4 Statistical results from two-way ANOVA examining response variables (participant knowledge of biological evolution and participant acceptance of biological evolution) by both theistic view and area of expertise

\begin{tabular}{|c|c|c|c|c|c|}
\hline \multicolumn{6}{|l|}{ Knowledge of B. Evolution } \\
\hline & $d f$ & Sum Sq & Mean Sq & $F$ value & $p$ value \\
\hline Theistic View & 1 & 2.0396 & 2.03963 & 55.0097 & $<0.001$ \\
\hline Area of Expertise & 8 & 0.7853 & 0.09816 & 2.6475 & $<0.01$ \\
\hline Theistic View: Area of Expertise & 8 & 0.0680 & 0.00851 & 0.2294 & $=0.985278$ \\
\hline Residuals & 264 & 9.7885 & 0.03708 & & \\
\hline \multicolumn{6}{|l|}{ Adjusted R squared: 0.1784} \\
\hline \multicolumn{6}{|l|}{ Acceptance of B. Evolution } \\
\hline & $d f$ & Sum Sq & Mean Sq & F value & $p$ value \\
\hline Theistic View & 1 & 16610.4 & 16610.4 & 178.4005 & $<0.001$ \\
\hline Area of Expertise & 8 & 1237.0 & 154.6 & 1.6607 & $=0.108186$ \\
\hline Theistic View: Area of Expertise & 8 & 1922.7 & 240.3 & 2.5813 & $<0.01$ \\
\hline Residuals & 264 & 24580.3 & 93.1 & & \\
\hline Adjusted R squared: 0.4101 & & & & & \\
\hline
\end{tabular}


Table 5 Statistical results from two-way ANOVA examining response variable (participant knowledge of biological evolution and participant acceptance of biological evolution) by both theistic view and amount of science education

\begin{tabular}{|c|c|c|c|c|c|}
\hline \multicolumn{6}{|l|}{ Knowledge of Biological Evolution } \\
\hline & $d f$ & Sum Sq & Mean Sq & F value & $p$ value \\
\hline Theistic View & 1 & 2.0396 & 2.03963 & 55.7704 & $<0.001$ \\
\hline Amount of Science Education & 3 & 0.5074 & 0.16913 & 4.6245 & $<0.01$ \\
\hline Theistic View: Amount of Science Education & 3 & 0.1138 & 0.03792 & 1.0369 & $=0.376658$ \\
\hline Residuals & 274 & 10.0207 & 0.03657 & & \\
\hline \multicolumn{6}{|l|}{ Adjusted R squared: 0.1896} \\
\hline \multicolumn{6}{|l|}{ Acceptance of Biological Evolution } \\
\hline & $d f$ & Sum Sq & Mean Sq & F value & $p$ value \\
\hline Theistic View & 1 & 16610.4 & 16610.4 & 172.8039 & $<0.001$ \\
\hline Amount of Science Education & 3 & 600.9 & 200.3 & 2.0839 & $=0.10261$ \\
\hline Theistic View: Amount of Science Education & 3 & 801.4 & 267.1 & 2.7791 & $<0.05$ \\
\hline Residuals & 274 & 26337.6 & 96.1 & & \\
\hline Adjusted R squared: 0.391 & & & & & \\
\hline
\end{tabular}

evolution does change by theistic view, but only for those participants who identified as "other". If those participants are removed in the schema no interaction term is detected.

The results from the pairwise t-tests were extremely varied. The primary likely cause for this is that when the theistic view schema is used in conjunction with a division of the data by area of expertise, some of the resulting groups are too small to be used in statistical comparisons (e.g., there was only one participant from the physical science area of expertise that is grouped as a creationist). Nevertheless, significant differences were detected between several groups, particularly between the creationist and non-creationist groups (Additional file 1: Tables S8 and S9).

\section{AIC tests of model fit}

Using AIC we compared which model (theistic view, area of expertise, or amount of science education was the best fit to the data (knowledge of biological evolution and acceptance of biological evolution) (Table 6). In both cases the model using theistic view was the best fit (smallest AIC).

\section{Qualitative results}

Analysis of the text responses revealed the presence of nearly every misconception about science and biological evolution that have been reported in the literature. The most common statements either implicitly or explicitly stated that biological evolution (or science) was a belief and thus equivalent to other beliefs (e.g., creationism).

"I believe it would take perhaps many sources of data and different "angles" of contradictory data before replacing an established scientific idea. That said, I do feel we sometimes hold too tight to old and out-dated belief systems." (Emphasis added)

"While we all have different beliefs, I believe it is important to teach both views so college students are aware of both positions. They then need to make their own choices. (I don't have to believe in evolution but I do believe students should be aware of the variety of beliefs" (Emphasis added)

Another misconception identified in the text responses was confusion regarding how biological evolution works. Multiple participants stated that biological evolution includes (or is) an explanation for the origin of life. As has been pointed out in other publications (Rice et al. 2010) this not the case, but it is a common misconception, even amongst some scientists (Paz-y-Miño and Espinosa 2011a; 2011b; 2012). Other participants stated that biological evolution was an entirely random/undirected process. Still others made incorrect statements about how natural selection works.
"Both biological evolution and intelligent design/ creationism should be taught in college science classes and given equal time with respect to discussions about how life originated on earth. The aspects of biological evolution that would explain how life is changing today, which can and have been observed and experienced experimentally, should also be taught with an emphasis on understanding how human interactions with the environment we live in impacts the ecosystem" (Emphasis added) 
Table 6 Log-likelihood and AIC of models on knowledge of biological evolution and acceptance of biological evolution

\begin{tabular}{llll}
\hline Model & log-likelihood & AIC & No. of parameters \\
\hline Knowledge of Biological Evolution Theistic View & 61.93252 & -117.8650 & 3 \\
Knowledge of Biological Evolution Area of Expertise & 46.61274 & -73.22549 & 10 \\
Knowledge of Biological Evolution Amount of Science Education & 45.34678 & -80.69356 & 5 \\
Acceptance of Biological Evolution Theistic View & -1047.150 & 2100.301 & 3 \\
Acceptance of Biological Evolution Area of Expertise & -1106.2 & 2232.4 & 10 \\
Acceptance of Biological Evolution Amount of Science Education & -1107.991 & 2225.982 & 5 \\
\hline
\end{tabular}

"By neglecting the supernatural as a possibility, scientists have eliminated one possible explanation of the origins of the natural world. As a result, many when confronted with the overwhelming evidence that life could not have randomly started on this planet, ascribe our presence here to extraterrestrial involvement." (Emphasis added)

Finally, there was little agreement from the participants regarding which "side" of the BEE issue the investigators were on. Some participants seemed convinced that the survey was designed with an inherent bias against people with creationist views and that the results would be used to attack religion. Other participants appeared equally convinced that the investigators were on the "side" of the creationists and would use the results to attack the teaching of biological evolution. We take this result as evidence that the survey was not inherently biased to either "side".

"God" help us if you are teaching Intelligent Design as fact".

"I wish you the best in your research. I hope that you're trying to better understand why people misunderstand evolution, and how we can convince people of the truth (as empirically and scientifically determined)".

"Mentioned before. Glad to see it addressed and pray it is a true study. Curious to know what the study outcomes are for this study... / Bottom line, scientific community and Christian community have much the same in common. Just need to chill a bit. Don't make these results inflammatory no matter what you conclude about whatever it is you are studying. "Evolutionists need to STOP trying to convince people that God is not involved, and simply teach the evidence for and against evolution like any other scientific theory. Evolution has become confounded with the scientists' worldview, i.e., they use evolution to try to "enlighten" people that God is not necessary, with the underlying implication that God does not exist". "If you don't consider psychology a science, then I would suggest you're just as biased as the creationists who do consider creationism a science!"
"If you can use this to knock ID out of some peoples heads, it will make me happy".

\section{Discussion}

What is the driving force behind an individual's knowledge and acceptance of biological evolution? Some argue that an individual's exposure to science, particularly to content on biological evolution, has the greatest impact on their knowledge and acceptance of biological evolution. Others suggest that an individual's theistic view is the overriding determiner of their knowledge and acceptance of biological evolution. Determining the factors (and the strength of those factors relative to each other) that influence an individual's knowledge and acceptance of biological evolution is an important step in being able to properly address the current issues with Biological Evolution Education (BEE). The analyses described here provide several unique insights into the interplay of factors influencing knowledge and acceptance of biological evolution.

First, knowledge of biological evolution and acceptance of biological evolution are linked together for university faculty. Higher knowledge of biological evolution positively correlates with higher acceptance of biological evolution across the sample of university faculty. This is in agreement with previous work showing a relationship between knowledge and acceptance (Lawson and Worsnop, 1992; Rice et al., 2011; Scharmann et al., 2005).

This positive correlation is also present if the sample is broken down into distinct theistic views (creationist and non-creationist viewpoints). This suggests that regardless of their theistic view, for university faculty higher knowledge of biological evolution positively correlates with higher acceptance of biological evolution. This relationship between knowledge, acceptance, and theistic view is important, because it may mean that a person's knowledge of biological evolution and acceptance of biological evolution can be improved in tandem regardless of their underlying personal beliefs.

When the population was subdivided by participant area of expertise, the positive correlation between higher knowledge of biological evolution and higher acceptance of biological evolution was present for all types of expertise except Veterinary Medicine. The simple linear 
regression (SLR) and Mantel tests were not in agreement, with the SLR showing the positive correlation and the Mantel test showing no correlation in either direction for Veterinary Medicine participants. This may be due to the fact that there were few Veterinary Medicine participants overall and that none of the Veterinary Medicine participants identified as young earth creationists, leaving a gap that could have biased the result. The presence of this positive correlation across areas of expertise suggests that despite a person's choice of academic specialty, their knowledge of biological evolution and acceptance of biological evolution can be improved together.

Several comparisons within each area of expertise category were unable to be performed. Of primary interest was the presence/absence of any variation by theistic view. Unfortunately when the theistic view schema is used in conjunction with a division of the data by area of expertise, many of the resulting sub-groups are too small to be used in statistical comparisons. Even so, differences were detected between theistic views in the Life Science, Social Science, Engineering, and Not Answered groups (Additional file 1: Tables S8 and S9). This is unsurprising given both the expected variation within the population and the variation between theistic views in the overall data. Future research with larger sample sizes will likely be more effective at examining any within group variation in different areas of expertise.

Higher knowledge of biological evolution also positively correlates with higher acceptance of biological evolution across different levels of science education. This is the case for high, moderate, and low levels, but not for those participants who stated they had received no science education in college. This result makes sense, as one would expect that a person who is taught science would learn much of that science and likely accept it as accurate. Since we did not ask the participants to inform us regarding how much of their previous science was in the biological sciences, we cannot be certain how much exposure to biological evolution they may have previously had.

These results were expected, but reinforce the point that knowledge and acceptance of biological evolution are positively correlated. If improving the public's acceptance of evolution is a goal of science educators, then this result adds more support to the idea that effective instruction in biological evolution is an appropriate course of action.

Second, theistic view, when compared to area of expertise and amount of science education, has the most influence on the knowledge and acceptance of biological evolution of university faculty. While all three factors showed significant differences between their levels and knowledge and acceptance of biological evolution, theistic view has the more pervasive influence on both measures. In both the two-way ANOVA of theistic view and area or expertise and the two-way ANOVA of theistic view and amount of science education, participants' theistic view showed the stronger significant relationship with knowledge and acceptance. The AIC measure of the different models also supports theistic view being the strongest influencer of both knowledge and acceptance of biological evolution, as the models using theistic view had the smallest AIC values (Figure 2). This result has clear ramifications for the future of BEE. Keeping in mind that knowledge and acceptance were positively correlated regardless of the participant's theistic view, it begs the question "Is the most effective way to improve BEE to address theistic views?" The data appear to support answering this question in the affirmative, but whether such action is morally, ethically, or legally appropriate is a question that remains to be answered. In the author's experience, addressing the relationship/conflict between theism and science can be fruitful in both the short-term and long-term for students. That said, students can certainly be made aware of efforts like The Clergy Letter Project (2015) which advocates for understanding and accepting biological evolution and seeks to demonstrate that science and religion can be compatible. Additionally, one of many rationales for teaching about the nature of science in all science courses, but particularly in biology courses, is address philosophical issues that can reduce resistance to learning about biological evolution and thus enhance acceptance of it (Clough, 1994 \& 2006; NAS, 1998).

Another interesting result of this work is that for both measures of knowledge and acceptance of biological evolution, the more science education the participants reported receiving in college, the better they did on those measures. Those participants who stated that they had taken nine or more science courses in college scored significantly higher on both the measures of knowledge of biological evolution and acceptance of biological evolution, when compared to those participants who had received less. This suggests that with effective instruction in the sciences (particularly biological evolution) knowledge and acceptance of biological evolution can be improved. However, when we considered participants' amount of science education and their theistic view, we only detected an interaction when those participants who responded "other" were included in the analysis. A confounding factor may possibly be at work here, that some amount of self-selection for additional science education is biasing our results. For instance, those who reject biological evolution may be less likely to pursue further education in science in general and biology in particular. That said, recent work by Short and Hawley (2015) suggests that for some students, exposure to biological evolution concepts in a single course is not sufficient to alter their understanding or acceptance levels. However, at some point, further education in science would unlikely be a 


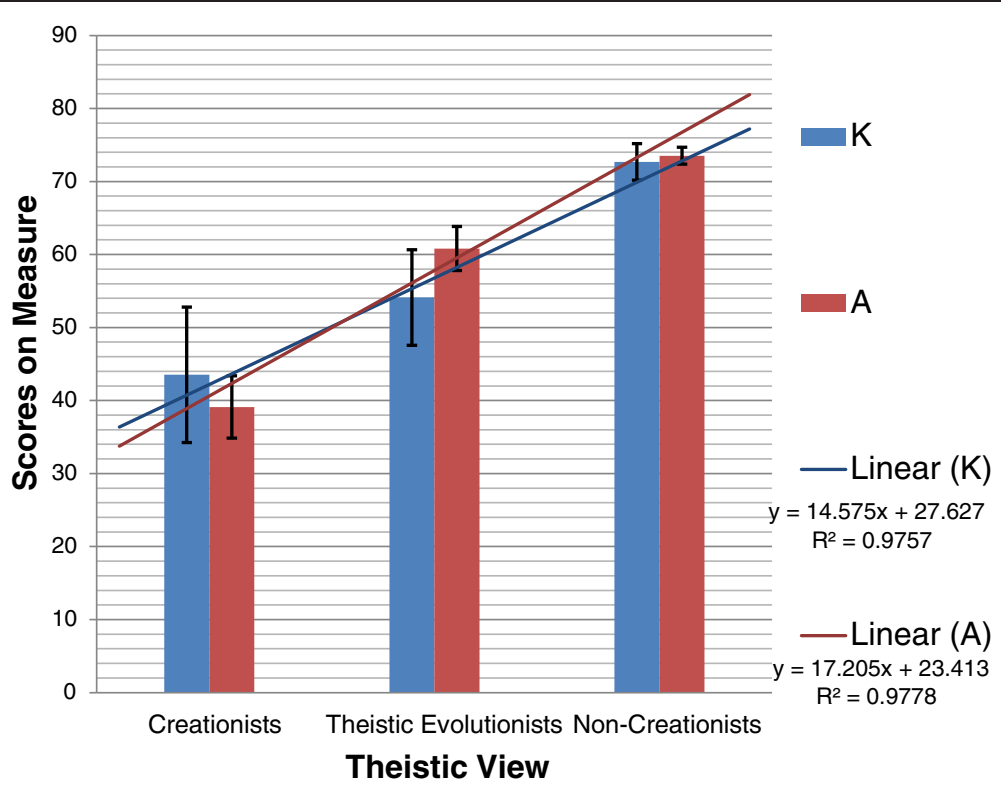

Figure 2 Best-fit model of participant average scores on knowledge of biological evolution measure $(K)$ and acceptance of biological evolution measure (A) when grouped by theistic view. Linear $\mathrm{K}=$ Best-fit line and coefficient of determination $(\mathrm{R} 2=0.975)$ for knowledge of biological evolution. Linear $A=$ Best-fit line and coefficient of determination ( $R 2=0.977)$ for acceptance of biological evolution. Bars $=95 \%$ C.I. around mean.

determining factor in acceptance of biological evolution. Future research should address how much engagement in biological evolution, with attention to the quality of that engagement, is needed for understanding and acceptance.

Consistent with previous studies, none of the other demographic measures (sex, age, tenure level) showed any relationship to either knowledge of evolution or acceptance of evolution. While we do not suggest that future researchers ignore these factors entirely, the consistency of this finding means that establishing this relationship is likely unnecessary in future research.

One sub-area of interest was examining participant delineation between their acceptance of human evolution compared to other aspects of evolution. Those participants who self-identified as having more creationist viewpoints were more likely to deny evolution in its entirely. Nearly all of those that self-identified as theistic evolutionists accepted both human and other aspects of evolution, with a few (three) separating the two concepts. All participants who self-identified as non-creationists accepted both human and other aspects of evolution.

It is interesting to compare the results seen here to similar previously studied groups. For example, approximately $15 \%$ of the 309 participants in this study held creationist theistic positions, while previous work has shown $24 \%$ of Louisiana high school biology teachers, 30\% of Minnesota high school biology teachers, and $62 \%$ of U.S. adults hold creationist theistic positions (Aguillard, 1999; Miller et al., 2006; Moore and Kramer, 2005). Clearly, university faculty at this study site have a lower rate of holding creationist views than groups in these prior studies. They also exhibit higher levels of knowledge and acceptance of biological evolution compared to previously studied groups (Rutledge and Sadler, 2007; Moore et al., 2009; Moore and Cotner, 2009a; Moore and Cotner, 2009b). Given the higher average level of education earned by the participants in this study compared to previous studies, this result is not unexpected. Noteworthy, however, is that the percentage of faculty in our sample who claim a personal belief in god is roughly twice that of the members of the National Academy of Sciences. This could be due to any number of factors, at personal, local, state, national, and/or international levels. For example, perhaps faculty who have creationist theistic positions see the state where this study site is located (Midwestern United States) as more friendly place to work than other less religious areas. Alternatively, faculty at this Midwest university may very well be more likely to have been raised in or near the Midwest, a region that opinion polls show have a higher professed belief in God than many other regions of the U.S.

Finally, the qualitative results from the participant text responses provide some valuable insight into the underlying thinking of university faculty. While some university faculty have serious misconceptions about biological evolution, not every response fell on the negative side of the ledger. Some participants demonstrated an extremely robust knowledge of not only biological evolution, but the issues surrounding BEE as well. 


\section{Conclusions}

The results presented here provide additional evidence to guide educators and researchers interested in effective BEE. Certainly the participants in this study had higher levels of knowledge and acceptance of biological evolution than those in other study populations. Even so, the average scores are well below $100 \%$. It is sobering that the average life science participant's score on the knowledge of biological evolution measure was only a $74.3 \%$ (a solid C in most college grading scales) and their score on the measure of acceptance was only $87.6 \%$. These are the participants who self-selected to study the biological sciences. If Dobzhansky's statement that "Nothing in Biology makes sense except in the light of evolution" is accurate, then how are these participants succeeding in their careers without basic knowledge and acceptance of biological evolution?

Both encouraging and disappointing is that faculty in this study, as a whole, accept biological evolution at a moderately high level (86.8\%). This percentage is encouraging when compared to Gallup polls that consistently report around $54 \%$ of the public accepts that biological evolution occurs. The well-known study by Miller, Scott, and Okamoto found that only about $40 \%$ of the American public think that biological evolution is true (Miller et al., 2006). However, that just short of $87 \%$ of faculty in our study accept biological evolution was disappointing given that these are some of the most highly educated members of American society. Additionally, the university faculty discussed here have a shared educational experience across their disciplines, such as significant opportunities for independent inquiry and research. Even when faculty are grouped by their theistic view, area of expertise, or amount of science education, only those participants that identified as social science, physical science, or having had a high amount of science education scored at or above the $90 \%$ level. We suggest that future research seek to compare individuals of various educational levels and backgrounds with a deeper look into their nature of science views, theological views, and understanding and acceptance of biological evolution.

Perhaps the most important result of this work is the evidence it provides that theistic view has a significant impact on both knowledge and acceptance of biological evolution. Additionally, it exerts more influence than either area of expertise or amount of science education. This is supported by the fact that the model using theistic view was the best fit according to the AIC measures used. The question remains, however, what do we do with this information? Should we as educators actively address our students' theistic views?

Without doubt, if educators want to promote acceptance of biological evolution, they must effectively promote a deep understanding of its most fundamental principles. All of the participants in this study were someone's students at one time, just as today's students are the citizens, educators, and policymakers of tomorrow. Addressing the problem at the faculty level needs to be one part of a larger, multi-pronged effort to get $\mathrm{BEE}$ in America to the point it should have been decades ago.

Finally, merely examining knowledge and acceptance of biological evolution is insufficient for a robust understanding of how to address the problems of BEE. Future research should determine what NOS understanding is most important for understanding and accepting biological evolution. Some previous research on BEE has included a NOS portion, but typically the there is little consistency regarding the instrument used (AAAS 1993; Alters and Nelson, 2002; Bell et al., 1998; Farber, 2003; Johnson and Peeples, 1987; NAS, 1998; Rutledge and Warden, 1999; Rutledge and Mitchell, 2002; Scharmann \& Harris, 1992; Smith, 2010; Southerland and Sinatra, 2003). Some studies have shown knowledge of biological evolution to be correlated with understanding of the NOS while other studies have shown that acceptance of biological evolution is correlated with understanding of the NOS. What is needed now are studies where all three of these variables are measured simultaneously to see if they are correlated. If that is the case then it would be strong evidence that effective BEE must include content on biological evolution; it must address acceptance of biological evolution, and it must include content on and address relevant issues in the NOS. Finally, studies ought to also examine more deeply the theological views of those who do and do not accept biological evolution. As the Clergy Letter Project makes clear, many devoutly religious individuals maintain a deep commitment to a personal deity while also accepting biological evolution. Understanding this view and how it develops may be instrumental in advancing understanding and acceptance of biological evolution.

\section{Additional files}

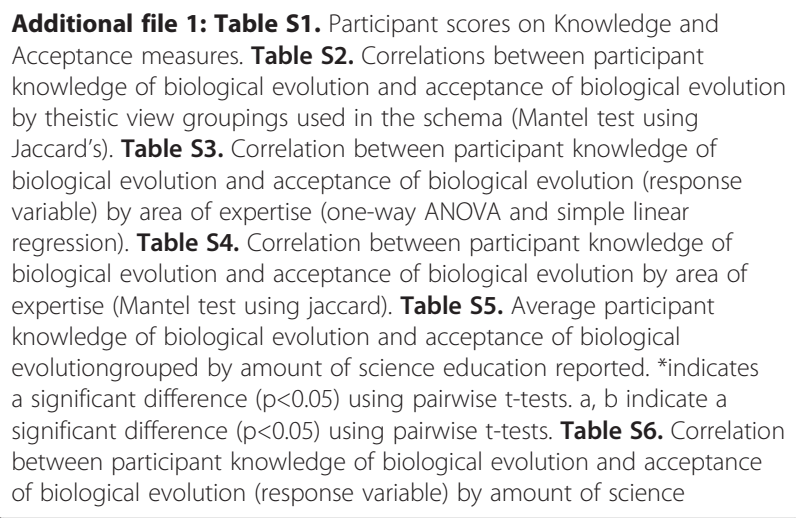

Additional file 1: Table S1. Participant scores on Knowledge and Acceptance measures. Table S2. Correlations between participant knowledge of biological evolution and acceptance of biological evolution by theistic view groupings used in the schema (Mantel test using Jaccard's). Table S3. Correlation between participant knowledge of biological evolution and acceptance of biological evolution (response variable) by area of expertise (one-way ANOVA and simple linear regression). Table S4. Correlation between participant knowledge of biological evolution and acceptance of biological evolution by area of expertise (Mantel test using jaccard). Table S5. Average participant knowledge of biological evolution and acceptance of biological evolutiongrouped by amount of science education reported. *indicates a significant difference $(p<0.05)$ using pairwise t-tests. $a$, b indicate a significant difference $(p<0.05)$ using pairwise t-tests. Table S6. Correlation between participant knowledge of biological evolution and acceptance of biological evolution (response variable) by amount of science 
education reported (one-way ANOVA and simple linear regression). Table S7. Correlation between participant knowledge of biological evolution and acceptance of biological evolution by amount of science education (Mantel test using Jaccard). Table S8. Statistical results from pairwise t-tests examining participant knowledge of biological evolution by their theistic viewpoint grouped by area of expertise. Table S9. Statistical results from pairwise t-tests examining participant acceptance of biological evolution by their theistic viewpoint grouped by area of expertise.

Additional file 2: Figure S1. A: PCOA of participant knowledge of evolution scores coded by theistic view. B: PCoA of participant knowledge of evolution scores coded by academic group. C: PCoA of participant knowledge of evolution scores coded by amount of science education. Legend $\sim$ Figure A: red $=$ Y.E.C., orange $=$ O.E.C., yellow $=$ Thes Evo., green $=$ Agnos. Evo., blue $=$ Athe. Evo., white $=$ NA/Other. Figure B: pink $=$ Social Science, red $=$ Physical Science, orange $=$ Business, yellow $=$ Applied Science/Engineering, green = Life Science, blue = Humanities, white $=$ Veterinary Medicine, gray $=$ Formal Science $/$ Math, black $=$ Not Answered. Figure C: pink $=5-8$ science courses, red $=1-4$ science courses, green $=$ no science courses, blue $=9$ or more science courses.

\section{Abbreviations}

NOS: The nature of science / nature of science; BEE: Biological evolution education; KEE: Knowledge of evolution exam; MATE: Measure of acceptance toward evolution; SUSSI: Student understanding of science and science inquiry; PCoA: Principal coordinate analysis; AIC: Akaike information criterion; NAS: National academy of science.

\section{Competing interests}

The authors declare that they have no competing interests.

\section{Authors' contributions}

JR conceived of the study, participated in the design and coordination stages, performed the statistical analyses with DA, and drafted the manuscript. MC participated in the design stage and helped to draft the manuscript. JO participated in the design stage, helped to draft the manuscript, and assisted with the statistical analyses. DA participated in the design stage and performed the statistical analyses with JR. JC participated in the design and coordination stages and helped to draft the manuscript. All authors read and approved the final manuscript.

\section{Acknowledgements}

We would like to thank our two reviewers for their comments and suggestions. IRB human subjects' approval was given on October 182010 (IRB \#10-474).

\section{Author details}

${ }^{1}$ Department of Life Sciences, Palmer College, Davenport, IA 52803-5287, USA.

${ }^{2}$ School of Education, lowa State University, Ames, IA 50011-3198, USA.

${ }^{3}$ Department of Ecology, Evolution, and Organismal Biology, lowa State University, Ames, IA 50011-3198, USA.

\section{Received: 11 December 2014 Accepted: 16 April 2015}

\section{Published online: 06 May 2015}

\section{References}

Alters, BJ, \& Alters, SM. (2001). Defending Evolution: A guide to the creation/ evolution controversy. Massachusetts: Jones and Bartlett Publishers.

Alters, BJ, \& Nelson, CE. (2002). Perspective: Teaching Evolution In Higher Education. Evolution., 56(10), 1891-1901.

American Association for the Advancement of Sciences (AAAS). (1993). Benchmarks for science literacy. New York: Oxford University Press.

Bandoli, JH. (2008). Do State Science Standard Matter? The American Biology Teacher., 70(4), 212-216.

Barnes, RM, Keilholtz, LE, \& Alberstadt, AL. (2009). Creationism and Evolution beliefs among college students. Skeptic., 14(3), 13-16.

Beardsley, PM. (2004). Middle School Student Learning in Evolution: Are Current Standards Achievable? The American Biology Teacher, 66(9), 604-612.

Bell, RL, Abd-El-Khalick, F, \& Lederman, NG. (1998). Implicit Versus Explicit Nature of Science Instruction: An Explicit Response to Palmquist and Finley. Journal of Research in Science Teaching., 35, 1057-1061.
Bowman, KL. (2008). The evolution battles in high-school science classes: who is teaching what? Frontiers in Ecology and the Environment., 6(2), 69-74.

Brem, SK, Ranney, R, \& Schindel, J. (2003). Perceived consequences of evolution: College students perceive negative personal and social impact in evolutionary theory. Science Education., 87(2), 181-206.

Cavanagh, S. (2005). Treatment of evolution inconsistent. Education Week., $25,111-21$.

Clough, MP. (1994). Diminish Students' Resistance to Biological Evolution. The American Biology Teacher., 56(7), 409-415.

Clough, MP. (2006). The Essential Role of the Nature of Science in Learning about Evolutionary Biology: Strategies for Enhancing Acceptance of Evolution. In Chapter I-6 in W.F. McComas (Ed.), Investigating Evolutionary Biology in the Laboratory (pp. 69-81). Dubuque: Kendall Hunt.

Colburn, A, \& Henriques, L. (2006). Clergy views on evolution, creationism, science, and religion. Journal of Research in Science Teaching., 43(4), 419-442.

Farber, P. (2003). Teaching Evolution and The Nature of Science. The American Biology Teacher., 65(5), 347-354.

Gross, L. (2006). Scientific Illiteracy and the Partisan Takeover of Biology. Public Library of Science: Biology., 4(5), e167.

Hawkins, DI, \& Coney, KA. (1981). Uninformed Response Error in Survey Research. Journal of Marketing Research, 18(3), 370-374.

Ingram, EL, \& Nelson, CE. (2006). Relationship between achievement and students' acceptance of evolution or creation in an upper-level evolution course. Journal of Research in Science Teaching., 43(1), 7-24.

Johnson, RL, \& Peeples, EE. (1987). The Role of Scientific Understanding in College: Student Acceptance of Evolution. The American Biology Teacher, 49(2), 93-96+98.

Lawson, AE, \& Worsnop, WA. (1992). Learning about Evolution and Rejecting a Belief in Special Creation: Effects of Reflective Reasoning Skill, Prior Knowledge, Prior Belief and Religious Commitment. Journal of Research in Science Teaching., 29(2), 143-166.

Liang, LL, Chen, S, Chen, X, Kaya, ON, Adams, AD, Macklin, M, \& Ebenezer, J. (2008). Assessing preservice elementary teachers' views on the nature of scientific knowledge: A dual-response instrument. Asia-Pacific Forum on Science Learning and Teaching., 9(1), 1-20.

Losh, SC, \& Nzekwe, B. (2010). Creatures in the classroom: Attitudes and beliefs about fantastic beasts, extraterrestrials, and creationism among education majors. Chicago: Paper presented at the American Association for Public Opinion Research meetings.

Miller, JD, Scott, EC, \& Okamoto, S. (2006). Public Acceptance of Evolution. Science., 313(5788), 765-766.

Moore, R, \& Cotner, S. (2009a). Educational Malpractice: The Impact of Including Creationism in High School Biology Courses. Evolution: Education and Outreach, 1(2), 95-100.

Moore, R, \& Cotner, S. (2009b). The Creationist Down the Hall: Does It Matter When Teachers Teach Creationism? BioScience, 5(59), 429-435.

Moore, R, \& Kraemer, K. (2005). The Teaching of Evolution and Creationism in Minnesota. The American Biology Teacher., 67(8), 457-466.

Moore, R, Cotner, S, \& Bates, A. (2009). The Influence of Religion and High School Biology Courses on Students' Knowledge of Evolution When They Enter College. The Journal of Effective Teaching., 9(2), 4-12.

National Academy of Sciences. (1998). Teaching About Evolution and the Nature of Science. Washington, DC: National Academy Press.

Nehm, RH, \& Schonfeld, I. (2007). Does Increasing Biology Teacher Knowledge of Evolution and the Nature of Science Lead to Greater Preference for the Teaching of Evolution in Schools? Journal of Science Teacher Education., 18(5), 699-723.

Paz-y-Miño, CG, \& Espinosa, A. (2011). New England faculty and college students differ in their views about evolution, creationism, intelligent design, and religiosity. Evolution: Education and Outreach., 4, 323-342.

Paz-y-Miño, CG, \& Espinosa, A. (2012). Educators of prospective teachers hesitate to embrace evolution due to deficient understanding of science/evolution and high religiosity. Evolution: Education and Outreach., 5, 139-162.

Paz-y-Miño, CG, \& Espinoza, A. (2011). On the Theory of Evolution Versus the Concept of Evolution: Three Observations. Evolution: Education and Outreach., 4, 308-312

R Core Team. (2014). R: A language and environment for statistical computing. Vienna, Austria: R Foundation for Statistical Computing. URL http://www.R-project.org/.

Rice, JW, Warner, DA, Kelly, CD, Clough, MP, \& Colbert, JT. (2010) The Theory of Evolution is Not an Explanation for the Origin of Life. Evolution: Education and Outreach, 3(2), 141-142. 
Rice, JW, Olson, JK, \& Colbert, JT. (2011). University Evolution Education: The Effect of Evolution Instruction on Biology Majors' Content Knowledge, Attitude Toward Evolution, and Theistic Position. Evolution: Education and Outreach, 4(1), 137-144.

Rudolph, JL, \& Stewart, J. (1998). Evolution and the Nature of Science: On the Historical Discord and Its Implications for Education. Journal of Research in Science Teaching., 35(10), 1069-1089.

Rutledge, ML, \& Mitchell, MA. (2002). High School Biology Teachers' Knowledge Structure, Acceptance and Teaching of Evolution. The American Biology Teacher., 64(1), 21-28.

Rutledge, ML, \& Sadler, KC. (2007). Reliability of the Measure of Acceptance of the Theory of Evolution (MATE) Instrument with University Students. The Biology Teacher, 6(69), 332-335.

Rutledge, ML, \& Warden, MA. (1999). The Development and Validation of the Measure of Acceptance of the Theory of Evolution Instrument. School Science and Mathematics, 1(99), 13-18.

Scharmann, LC, \& Harris, WM. (1992). Teaching Evolution: Understanding and Applying the Nature of Science. Journal of Research in Science Teaching, 29(4), 375-388.

Scharmann, LC, Smith, MU, James, MC, \& Jensen, M. (2005). Explicit Reflective Nature of Science Instruction: Evolution, Intelligent Design, and Umbrellaology. Journal of Science Teacher Education., 16(1), 27-41.

Scott, EC (2005). Evolution vs. Creationism: An Introduction. Berkeley and Los Angeles, California: University of California Press

Sinatra, GM, Southerland, SA, McConaughy, F, \& Demastes, JW. (2003). Intentions and beliefs in students' understanding and acceptance of biological evolution. Journal of Research in Science Teaching., 40(5), 510-528.

Sinclair, A, \& Pendarvis, MP. (1998). Evolution vs. Conservative Religious Beliefs. Journal of College Science Teaching, 3(27), 167-170.

Smith, MU. (2010). Current Status of Research in Teaching and Learning Evolution: I. Philosophical/Epistemological Issues. Science and Education., 19(6-8), 523-538.

Southerland, SA, \& Sinatra, GM. (2003). Learning about biological evolution: A special case of intentional conceptual change. In GM Sinatra \& PR Pintrich (Eds.), Intentional conceptual change (pp. 1-18). Mahwah, NJ: Erlbaum.

The Clergy Letter Project. 2015. 8 September $2011<$ <ttp://www.theclergyletter project.orgevolution.berkeley.edu/>.

Tull, DS, \& Hawkins, DI. (1993). Marketing Research: Measurement and Method. New York: Macmillan Publishing.

Understanding Evolution. 2015. University of California Museum of Paleontology. 8 September $2011<$ http://evolution.berkeley.edu/>.

Van Koevering, TE, \& Stiehl, RB. (1989). Evolution, Creation and Wisconsin Biology Teachers. The American Biology Teacher, 4(51), 200-202.

Verhey, SD. (2005). The Effect of Engaging Prior Learning on Student Attitudes toward Creationism and Evolution. BioScience., 55(11), 996-1003.

Wallis, C. (2005). The Evolution Wars. Time, 166(7), 26-35.

Zimmerman, M. (1987). The Evolution-Creation Controversy: Opinions of Ohio High School Biology Teachers. Ohio Journal of Science., 87(4), 115-125.

\section{Submit your manuscript to a SpringerOpen ${ }^{\circ}$ journal and benefit from:}

- Convenient online submission

- Rigorous peer review

- Immediate publication on acceptance

- Open access: articles freely available online

- High visibility within the field

- Retaining the copyright to your article

Submit your next manuscript at $\gg$ springeropen.com 